\title{
Effect of inhaled Piriprost (U-60, 257) a novel leukotriene inhibitor, on allergen and exercise induced bronchoconstriction in asthma
}

\author{
J S MANN, C ROBINSON, A Q SHERIDAN, P CLEMENT, M K BACH, \\ S T HOLGATE
}

From Medicine I, Southampton General Hospital, Southampton, and Upjohn Company, Kalamazoo, Michigan, USA

ABSTRACT The leukotrienes, a group of oxidative metabolites of arachidonic acid, have potent pharmacological actions on human airways. We have investigated the effects of a leukotriene synthesis inhibitor, piriprost (U-60, 257) administered by inhalation on allergen and exercise induced bronchoconstriction in 12 subjects with allergic asthma. Subjects underwent diagnostic challenges with allergen and treadmill exercise to define the strengths of the stimuli required to reduce the $\mathrm{FEV}_{1}$ to about $25 \%$ of baseline ( $\mathrm{PS}_{25}$ ). On separate study days subjects inhaled either piriprost $1 \mathrm{mg}$ or vehicle placebo, followed 15 minutes later by the $\mathrm{PS}_{25}$ allergen or exercise. The $\mathrm{FEV}_{1}$ was measured at regular intervals before and after challenge up to 60 minutes. After allergen challenge in six subjects peak expiratory flow (PEF) was measured for the following 20 hours. When compared with placebo, inhalation of piriprost had no significant protective effect on the fall in FEV at any time point within 60 minutes of allergen or exercise challenge. In the four subjects with a documented late asthmatic reaction 2-12 hours after allergen challenge piriprost had no protective effect when compared with placebo. In the subjects who recorded PEF over 20 hours after allergen challenge there was no significant difference between piriprost and placebo. Piriprost was appreciably more irritant to the respiratory tract than was placebo. On the assumption that inhaled piriprost was bioavailable in the airways, this study casts doubt on any theory of a pivotal role for leukotrienes in the pathogenesis of acute exercise and allergen induced airway bronchoconstriction in asthma.

The sulphidopeptide leukotrienes represent some of the most potent proinflammatory mediators that have so far been described in man. Leukotrienes $\mathrm{C}_{4}\left(\mathrm{LTC}_{4}\right)$ and $\mathrm{D}_{4}\left(\mathrm{LTD}_{4}\right)$ are up to 1000 times more potent than histamine as contractile agonists for human bronchi in vitre. ${ }^{12}$ When given to man by inhalation leukotrienes are powerful bronchoconstrictors in normal and asthmatic subjects, although asthmatic subjects appear to be relatively less reactive to leukotrienes than to histamines. ${ }^{34}$ In addition to their dynamic effects on airway smooth muscle, leukotrienes cause constriction and increased permeability of the microvasculature and stimulate mucus secretion from bronchial mucus glands. ${ }^{5}$

Address for reprint requests: Dr S T Holgate, Southampton General Hospital, Southampton SO94XY.

Accepted 3 June 1986
Although there is convincing evidence that the $\operatorname{IgE}$ dependent stimulation of human lung results in the synthesis and release of $\mathrm{LTC}_{4}$ and $\mathrm{LTD}_{4},{ }^{6-8}$ there is still debate about whether these mediators originate from mast cells. ${ }^{9}$ A recent study ${ }^{10}$ has shown that IgE dependent stimulation of bronchoalveolar lavage cells containing $0 \cdot 1-1 \cdot 0 \%$ mast cells initiates the release of large amounts of histamine and prostglandin (PG) $\mathrm{D}_{2}$ in parallel but only a small quantity of $\mathrm{LTC}_{4}$, which does not correlate with histamine release.

In addition to the sulphidopeptide leukotrienes, the $5 S$, 12R-dihydroxyeicosatetranoeic acid $\mathrm{LTB}_{4}$ is believed to be important in inflammatory reactions. ${ }^{11}$ This compound is a potent chemotactic factor for neutrophils ${ }^{12}$ and eosinophils, ${ }^{13}$ and its release may contribute to the cellular infiltrate that characterises the late asthmatic reaction, increased non-specific 
bronchial responsiveness, ${ }^{14}$ and more chronic forms of asthma.

There is therefore considerable interest in the pharmacological potential of drugs that may inhibit the synthesis or block the actions of leukotrienes. Piriprost (6,9-deepoxy-6,9-(phenylimino)- $\Delta^{6,8}$-prostaglandin $\mathrm{I}_{1}(\mathrm{U}-60,257)$, an analogue of prostacyclin, is a potent inhibitor of 5-lipoxygenase product formation in rat peritoneal mononuclear cells, ${ }^{15}$ human asthmatic lung fragments ${ }^{16}$ and dispersed cells, ${ }^{17}$ neutrophil leucocytes, ${ }^{18}$ and eosinophils. ${ }^{19}$ At higher concentrations it is a receptor antagonist of sulphidopeptide leukotrienes. $^{20}$ In vivo, piriprost inhibits the IgE dependent bronchoconstriction induced by inhaled Ascaris suum in sensitised rhesus monkeys ${ }^{21}$ and it is a potent inhibitor of canine tracheal mucus secretion. ${ }^{22}$ In this paper we report a double blind evaluation of a single inhaled dose of piriprost to protect against allergen and exercise induced bronchoconstriction in asthmatic subjects.

\section{Methods}

\section{SUBJECTS}

Nine men and three women with asthma (mean (SEM) age $24(1.3)$ y) took part in the study. On entry all patients were within $15 \%$ of their ideal weight and had normal haemoglobin concentration, peripheral leucocyte count, liver function, urea and electrolyte concentrations, and urine analysis, and had a normal chest radiograph and electrocardiogram. All patients were using intermittent inhaled $\beta_{2}$ adrenoceptor agonists, but none required chronic treatment with corticosteroids, long acting antihistamines, or theophylline preparations. All subjects had positive skin reactions to extracts of at least two common allergens. Written informed consent was obtained from each patient and the study was approved by the Southampton University Hospital's ethical subcommittee.

\section{BRONCHIAL PROVOCATION AND AIRWAY}

\section{MEASUREMENTS}

Exercise was carried out at room temperature on a treadmill adjusted to a speed of $6 \mathrm{~km} / \mathrm{h}$. The incline of the treadmill was set at $5-15 \%$ and exercise performed for five minutes. ${ }^{23}$ The bronchial provocation with allergen was carried out by a method modified from that of Chai et al. ${ }^{24}$ Extracts of grass pollen or house dust mite (Bencard, Brentford, Middlesex) were administered as a single nebulised dose from an Inspiron Mini-neb nebuliser (Inspiron, CR Bard, Sunderland) driven by air at a flow rate of $81 \mathrm{~min}^{-1}$. This delivers $0.33 \mathrm{ml}$ of aerosolised solution a minute. The subjects were asked to take five deep breaths from residual volume to total lung capacity, during which aerosolised allergen (mass median particle diameter $4.7 \mu \mathrm{m}$ ) was inhaled.

The same exercise and allergen challenges were used on each of the study days. Before and at regular time points after each challenge $\mathrm{FEV}_{1}$ was measured with a Vitalograph dry wedge spirometer, the better of two recordings being used for analysis.

Piriprost $2 \mathrm{mg}$ (Upjohn Co, Kalamazoo, Michigan, USA) was dissolved in $200 \mu \mathrm{l}$ of $10 \mathrm{mg} / \mathrm{ml}$ tris (hydroxymethylamino)methane buffered saline, to which $3.8 \mathrm{ml}$ of nitrogen purged $0.9 \%$ saline solution was added. The nebulisers were sealed under a blanket of nitrogen, stored at $4^{\circ} \mathrm{C}$, and protected from light until used. Vehicle solutions were prepared similarly but without piriprost. Neither the investigator nor the subjects were aware of the contents of the nebulisers.

\section{BLOOD MEASUREMENTS}

At the start and immediately after completion of each of the protocols routine urine analysis was undertaken and blood withdrawn for full blood count; platelet count; liver function tests; and determination of the concentrations of urea, electrocyte, and blood glucose.

\section{STUDY PROTOCOL}

Subjects attended the laboratory on six separate days at least one week apart. Before each visit all treatment was omitted for 12 hours. On three consecutive visits subjects underwent a five minute exercise challenge on the treadmill. On the remaining study days allergen bronchial provocation was performed. An initial test was performed to determine the strength of exercise and allergen stimuli required to produce a $25 \%$ fall in $\mathrm{FEV}_{1}$. After three baseline measurements of $\mathrm{FEV}_{1}$, subjects underwent exercise challenge to define the slope of the treadmill necessary to induce bronchoconstriction to a maximum $25 \%$ fall in $\mathrm{FEV}_{1}$. On the first allergen day increasing concentrations of the allergen extract to which the subject was most sensitive on skinprick testing were administered by inhalation at five minute intervals until a $25 \%$ fall in $\mathrm{FEV}_{1}$ occurred.

On the drug study days subjects attended the laboratory to inhale either piriprost $(0.5 \mathrm{mg} / \mathrm{ml}$ in a total volume of $4 \mathrm{ml}$ ) or matched vehicle placebo. Subjects inhaled the drug or placebo for six minutes, breathing tidally through a mouthpiece from a preweighed Mini-neb disposable nebuliser. The nebuliser was reweighed after use to ensure that $1 \mathrm{mg}$ drug had been delivered. Fifteen minutes after inhalation of the aerosols baseline recordings of $\mathrm{FEV}_{1}$ were made. Subjects then underwent either exercise challenge or allergen provocation followed by measurements of FEV $_{1}$ at 5, 10, 15, 30, 45, and 60 minutes. After aller- 


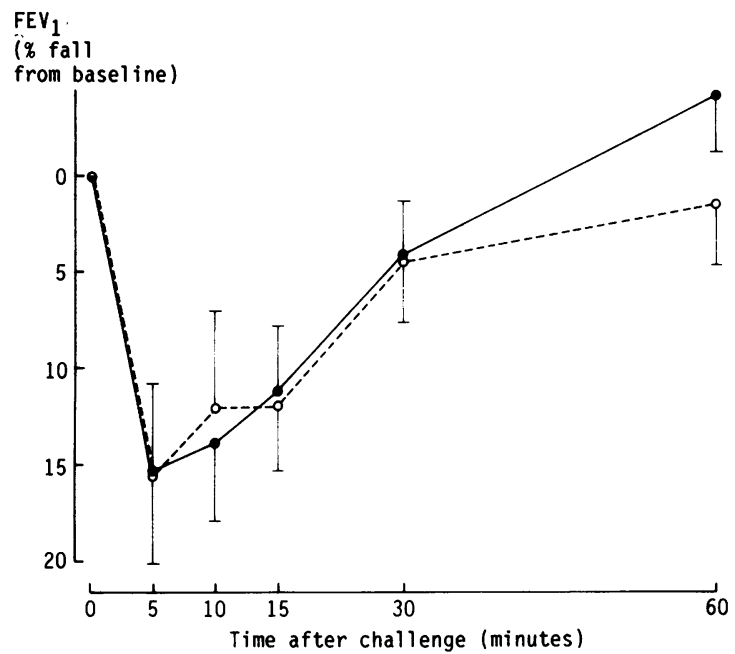

Fig 1 Effect of inhaled piriprost (1 $\mathrm{mg}$ ) (O- or placebo vehicle ( $\mathrm{O}----\mathrm{O}$ ) on the immediate change in $F E V_{1}$ after treadmill exercise. Each point represents the mean and standard error for observations made on 12 subjects. There were no significant differences between piriprost and placebo at any time point.

gen challenge nine subjects recorded peak expiratory flow rate measurements (PEF) with a Mini-Wright peak flow meter for the next 20 hours to monitor any late asthmatic reaction or change in morning PEF. Blood pressure and heart rate were measured before and after the study.

\section{ANALYSIS OF DATA}

The responses of $\mathrm{FEV}_{1}$ to allergen and exercise provocation were plotted as absolute values and as percentage changes from baseline after drug or placebo, and mean values were calculated. The area under individual time course-response curves was calculated by trapezoid integration. ${ }^{25} \mathrm{~A}$ two way analysis of variance was used to compare the effect of drug and placebo on $\mathrm{FEV}_{1}$ at each time point after challenge and on maximum fall in $\mathrm{FEV}_{1}$ for each
FEV 1

(\% fall

from baseline)

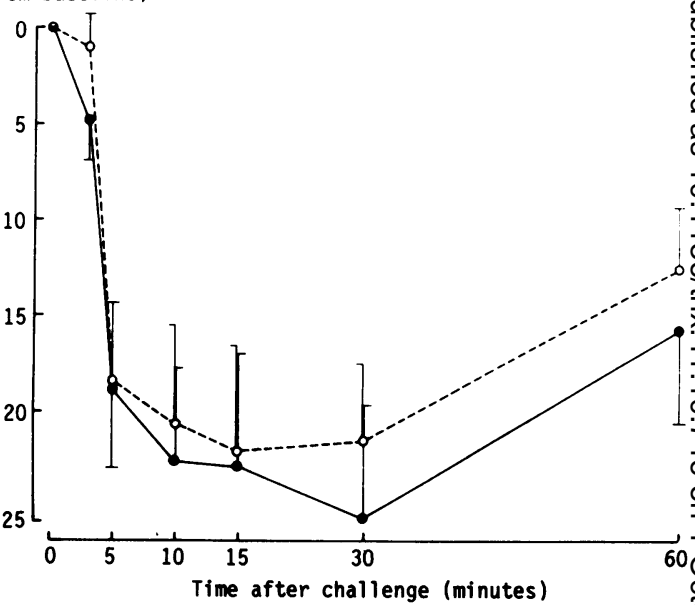

Fig 2 Effect of inhaled piriprost (1 mg) (- - or placebo vehicle ( $\mathrm{O}----\mathrm{O})$ on the immediate changes in $F E V_{1}$ after allergen provocation (time zero). Each point represents the mean and standard error for observations made on 12 subjects. There were no significant differences between piriprost and placebo at any time point.

challenge irrespective of time. A decrease of more than $15 \%$ in PEF from the prechallenge baseline occurring 3-10 hours after allergen challenge was considered to indicate a late reaction.

\section{Results}

Baseline measurements of $\mathrm{FEV}_{1}$ after placebo or piriprost were not significantly different when patients attended for exercise (mean (SEM) 3.11 $(0 \cdot 11)$ and $3.06(0 \cdot 08) 1)$ and allergen $(3 \cdot 12(0 \cdot 12)$ and $3 \cdot 23(0 \cdot 12)$ l) provocation. After exercise the $\mathrm{FEV}_{1}$ fell in all subjects to a minimum, irrespective of time after provocation, of $2.41(0 \cdot 18) 1(19 \cdot 8 \%$ fall from baseline) after inhaled piriprost, and $2.51(0 \cdot 19) 1(18.7 \%$ fall) after placebo. There was no significant difference between piriprost and placebo in the maximum fall in

Table 1 Effect of piriprost and placebo on minimum peak expiratory flow $\left(l \mathrm{~min}^{-1}\right)$ recorded during an allergen induced rate reaction in four subjects

\begin{tabular}{|c|c|c|c|}
\hline \multicolumn{2}{|l|}{ Placebo } & \multicolumn{2}{|l|}{ Piriprost } \\
\hline $2 h$ after challenge & Minimum PEF 3-12 $h^{*}$ & $2 \mathrm{~h}$ after challenge & Minimum PEF 3-12h \\
\hline $\begin{array}{l}450 \\
500 \\
370 \\
500 \\
\text { Mean (SEM) } 455(31)\end{array}$ & $\begin{array}{l}180(10 h)^{*} \\
440(12 \mathrm{~h}) \\
290(5 \mathrm{~h}) \\
420(13 \mathrm{~h}) \\
333(61)\end{array}$ & $\begin{array}{l}410 \\
520 \\
400 \\
500 \\
458(32)\end{array}$ & $\begin{array}{l}240(6 \mathrm{~h}) \\
470(11 \mathrm{~h}) \\
295(3 \mathrm{~h}) \\
460(5 \mathrm{~h}) \\
366(58)\end{array}$ \\
\hline
\end{tabular}

*Time of minimum PEF recording. 
Table 2 Effect of piriprost and placebo on peak expiratory flow rate $\left(\mathrm{lmin}^{-1}\right) 18$ hours after allergen challenge in six subjects

\begin{tabular}{|c|c|c|c|}
\hline \multicolumn{2}{|l|}{ Placebo } & \multicolumn{2}{|l|}{ Piriprost } \\
\hline $2 \mathrm{~h}$ after challenge & 18 h after challenge* & $2 h$ after challenge & $18 \mathrm{~h}$ after challenge \\
\hline $\begin{array}{l}450 \\
310 \\
500 \\
405 \\
500 \\
360 \\
\text { Mean (SEM) } 421(31)\end{array}$ & $\begin{array}{l}500 \\
240 \\
390 \\
295 \\
450 \\
290 \\
361(42)\end{array}$ & $\begin{array}{l}500 \\
370 \\
520 \\
410 \\
500 \\
360 \\
443(29)\end{array}$ & $\begin{array}{l}500 \\
150 \\
400 \\
280 \\
450 \\
290 \\
345(53)\end{array}$ \\
\hline
\end{tabular}

${ }^{*}$ Recorded at 8.30 am on the day after allergen challenge.

$\mathrm{FEV}_{1}$ irrespective of time after challenge, percentage fall from baseline, time taken to achieve the maximum fall in $\mathrm{FEV}_{1}$ at each time point (fig 1), rate of recovery of $\mathrm{FEV}_{1}$ after challenge, or the area under the fall in $\mathrm{FEV}_{1}$-time response curve.

Inhaled allergen also provoked an immediate fall in $\mathrm{FEV}_{1}$ to a minimum, irrespective of time after challenge, of $2.29(0.23) 1(27.6 \%$ of baseline) on the piriprost study day and $2.23(0 \cdot 2) 1(26.9 \%$ fall from baseline) on the placebo day. Again, there was no significant difference between these values on the drug and placebo study days, or the percentage fall of $\mathrm{FEV}_{1}$ from baseline, time taken to achieve the maximum fall in $\mathrm{FEV}_{1}$ at each time point (fig 2), rate of recovery of $F E V_{1}$ after challenge, or area under the allergen fall in $\mathrm{FEV}_{1}$-time response curve.

Four of the 12 patients experienced a late reaction 5-10 hours after allergen provocation after recovery from the immediate response. There was no difference between piriprost and placebo in the late asthmatic reaction as reflected by absolute falls in PEF or percentage change in this measurement from baseline (table 1).

In the six patients who recorded PEF at 8.30 am the day after allergen challenge there was no significant difference between post-piriprost and post-placebo values in PEF (345 (53) $1 \mathrm{~min}^{-1}$ and 361 (42) $1 \mathrm{~min}^{-1}$ ), or in the fall in peak flow rate overnight (98 (34) and 77 (12) $1 \mathrm{~min}^{-1}$ ) (table 2).

At no time during the study was any abnormality detected in blood or urine biochemisty or in blood pressure or heart rate after drug administration. During exercise provocation six patients complained of throat irritation or burning and three of wheezing after piriprost, whereas only one complained of wheezing, with no other symptoms, after placebo. In the allergen study one patient complained of cough, one of an altered sense of taste, eight of throat irritation or burning, and two of wheezing after piriprost, whereas only one had mild symptoms of rhinorrhoea during the placebo period $(p<0.01)$.

\section{Discussion}

In the present study piriprost, administered as an aerosol locally to the airways of 12 patients with asthma, did not confer any protection against the immediate bronchoconstrictor response induced either by inhaled allergen or by exercise. In a smaller group of subjects we were unable to show any protection from piriprost against the allergen induced late asthmatic reaction or in the fall in PEF on the morning after allergen challenge.

There are several possible interpretations of our findings. Firstly, at the dose used and administered by inhalation, piriprost may not have been bioavailable in the airways, because of either chemical instability, rapid absorption from the bronchi into the circulation, or enzymatic inactivation before it reached its site of action. In view of the documented instability of the drug, considerable care was taken in the preparation of the piriprost solutions; under the conditions we used the drug is stable for at least 10 hours. Nebulisation of a $1 \%$ solution prepared in the same manner, was sufficient to attenuate bronchoconstriction in sensitised rhesus monkeys challenged with Ascaris suum. ${ }^{21}$ Thus in non-human primates piriprost is unlikely to be inactivated when delivered to the airways. The dose administered in our subjects was about one fifth that administered to the monkeys and possibly insufficient drug was given to produce a pharmacological effect. In guinea pigs sensitised with ovalbumin, however, a calculated dose of inhaled piriprost of $5 \mu \mathrm{g}$ per animal $(1.5 \mu \mathrm{g} / \mathrm{kg})$ delivered to the airways was sufficient to attenuate allergen induced bronchoconstriction. ${ }^{26}$ This dose was in the same range as the dose given to the asthmatic subjects in the present study. With the method of nebulisation we used $12 \%$ of the solution leaving a Mini-neb nebuliser reaches the lungs and $90 \%$ of this material is deposited in the airways. ${ }^{27}$ There is no information on how the pharmacokinetics of inhaled piriprost in man compare with those in the monkey, although it 
remains possible that reduced bioavailability may have occurred as a result of a short pulmonarysystemic transit time. ${ }^{28}$

Another possibility is that piriprost did not act on mediator secreting cells in the airways. This seems an unlikely explanation for our negative results, since piriprost has been shown to inhibit both the immunological and the ionophore dependent generation of LTC $_{4}$ from human enzymatically dispersed lung cells $^{17}$ and lung fragments from normal ${ }^{20}$ and asthmatic $^{16}$ subjects, although in the case of dispersed cells reversal of inhibition was observed. ${ }^{17}$

The earliest phase $(0-10 \mathrm{~min})$ of the immediate asthmatic reaction can to a great extent be accounted for by the spasmogenic effect of released histamine ${ }^{2930}$ and in vivo may be antagonised by potent $\mathrm{H}_{1}$ histamine receptor antagonists such as astemizole. $^{31}$ The latter part of the response (10-30 min) may largely be attributed to the release of newly generated mast cell dependent mediators, which include $\mathrm{PGD}_{2}, \mathrm{LTC}_{4}$ and $\mathrm{LTD}_{4}$. In the present study the maximum degree of bronchoconstriction and the rate of recovery after allergen or exercise was not influenced by piriprost. The degree to which leukotrienes contribute to the immediate airway response to inhaled allergen in asthma has not been defined. If an $\mathrm{H}_{1}$ receptor antagonist, a cyclooxygenase inhibitor, and the addition of exogenous arachidonate were necessary for demonstrating optimal bioactivity of piriprost against allergen induced bronchoconstriction in guinea pigs, ${ }^{26} 32$ then similar steps may be necessary to show a similar drug effect in man. Moreover, the amount of $\mathrm{LTC}_{4}$ generated by IgE dependent challenge of human bronchoalveolar lavage cells is relatively small by comparison with the amount of mast cell derived $\mathrm{PGD}_{2}$ and histamine. ${ }^{10}$ By comparison with normal subjects, the airways of asthmatic patients are less hyperreactive to LTC $_{4}$ than to inhaled histamine ${ }^{2}$ or methacholine, ${ }^{5}$ the difference from normal subjects being smaller with $\mathrm{LTC}_{4}$ than with the latter two substances.

After allergen provocation some patients develop late bronchoconstrictor responses accompanied by an increase in non-specific airways reactivity six to nine hours after challenge, ${ }^{33}$ associated with a peripheral blood eosinophilia and a large increase in the number of eosinophils recovered by bronchoalveolar lavage. ${ }^{34}{ }^{35}$ It might be expected therefore that a drug capable of inhibiting the leukotriene generation pathway could also inhibit allergen induced release of LTB $_{4}$ and hence recruitment of secondary effector cells for the late reaction. In the present study four of the nine patients who recorded PEF during 12 hours after allergen challenge developed late asthmatic reactions, but this was similar after piriprost and placebo, despite the in vitro capacity of piriprost to inhibit
$\mathrm{LTB}_{4}$ generation from activated neutrophils ${ }^{18}$ and $\overrightarrow{\overline{\vec{s}}}$ LTC $_{4}$ generation from eosinophils. ${ }^{19}$

In a sheep model of the late asthmatic reaction $\overline{0}$ infiltration of the airways with leucocytes has been $\frac{\bar{\omega}}{\vec{D}}$ shown to correlate with the development of non- $\stackrel{\mathbb{Q}}{\mathscr{Q}}$ specific bronchial reactivity. ${ }^{36}$ In dogs exposed to low concentrations of ozone, Fabbri and co-workers have shown that BW755C, a dual inhibitor of the 5-lipoxygenase and cyclo-oxygenase pathways, $\vec{\omega}$ inhibits ozone induced hyperreactivity, ${ }^{37}$ suggesting $\stackrel{\omega}{\circ}$ that the chemotactic recruitment of inflammatory $\overrightarrow{\vec{x}}$ leucocytes plays an essential part in the development of increased airways reactivity with allergen exposure. We did not measure non-specific bronchial reactivity after allergen or exercise provocation but Ryan et al $^{38}$ के have shown that diurnal variation in airway calibre 0 closely reflects the degree of non-specific airways reactivity in asthma. In the present study we were unable $\overrightarrow{0}$ to find any effect of piriprost on the early morning falls of PEF in six asthmatic subjects or, by implication, any effect on non-specific bronchial reactivity.

Another possible explanation of our negative $\overrightarrow{0}$ findings is that by inhibiting the 5-lipoxygenase path- $\stackrel{\circ}{\circ}$ way piriprost may "shunt" arachidonic acid along the cyclo-oxygenase pathway to the mast cell bronchoconstrictor prostanoid $\mathrm{PGD}_{2} \cdot{ }^{39}$ Although we have shown that piriprost inhibits ionophore induced $\mathrm{LTC}_{4}$ generation by human enzymatically dispersed $\frac{\mathrm{D}}{\mathcal{2}}$ lung cells and also potentiates the generation of the mast cell derived bronchoconstrictor prostanoid $\frac{3}{3}$ $\mathrm{PGD}_{2},{ }^{40}$ it is important to note that the effects do not $\frac{3}{J}$ occur at comparable concentrations. ${ }^{17}$ Furthermore, in isolated lung cells piriprost also reverses the inhibition of $\mathrm{LTC}_{4}$ release at higher concentrations. ${ }^{17} \overrightarrow{\mathrm{\sigma}}$

In conclusion, this study has shown that piriprost, a potent inhibitor of leukotriene biosynthesis in vari- $-\dot{\sigma}$ ous cells in vitro, does not influence the airway responses after allergen and exercise bron- $\delta$ choprovocation in asthma. Although we had no positive control against which piriprost could be $ᄋ$ compared in man, studies in vitro and in vivo in animals indicate that, if products of the 5-lipoxygenase pathway contribute a major component to the immediate airway responses to allergen and exercise, then or at least some inhibitory effect should have been $\tilde{O}$ apparent. Our negative findings with this drug must put in question the extent to which leukotrienes and related products contribute as mediators of acute asthma provoked either by allergen or by exercise.

\section{References}

1 Dahlén SE, Hedquist P, Hammarström S, Samuelsson B. Leukotrienes are potent constrictors of human bronchi. Nature 1980;288:484-6. 
2 Dahlén SE. Pulmonary effects of leukotrienes. Acta Physiol Scand 1983;512(suppl):1-51.

3 Bisgaard H, Groth S, Flemming M. Bronchial hyperreactivity to leukotriene $D_{4}$ and histamine in exogenous asthma. $\mathrm{Br}$ Med $\mathrm{J}$ 1985;290:1468-71.

4 Smith LJ, Greenberger PA, Patterson R, Krell RD, Bernstein PR. The effect of inhaled leukotriene $\mathrm{D}_{4}$ in humans. Am Rev Respir Dis 1985;131:368-72.

5 Piper PJ. Pharmacology of leukotrienes. Br Med Bull 1983;39:255-9.

6 MacGlashan DW, Schleimer RP, Peters SP, Schulman ES, Adams GK III, Schulman ES, Newball HH, Lichtenstein LM. Generation of leukotrienes by purified human lung mast cells. $J$ Clin Invest 1982;70:747-51.

7 Schleimer RP, MacGlashan DW, Peters SP, et al. Inflammatory mediators and mechanisms of release from purified human basophils and mast cells. $J$ Allergy Clin Immunol 1984;74:473-81.

8 Harvey J, Holgate ST, Peters BJ, Robinson C, Walker JR. Oxidative transformation of arachidonic acid in human dispersed lung cells: disparity between utilization of endogenous and exogenous substrate. $\mathrm{Br} \mathrm{J}$ Pharmacol 1985;86:417-26.

9 Lewis RA, Mencia-Huerta J-M, Lee CW, Austen KF. Mast cell dependent synthesis of lipid mediators of immediate hypersensitivity. In: Kay AB, Austen KF, Lichtenstein LM, eds. Asthma: physiology, immunopharmacology and treatment. London: Academic Press, 1983:63-83.

10 Flint KC, Hudspith BN, Leung KBP, et al. IgEdependent release of leukotriene $\mathrm{C}_{4}$ and prostaglandin $\mathrm{D}_{2}$ from human bronchoalveolar cells [abstract]. Thorax 1985;40:717.

11 Goetzl EJ. Oxygenation products of arachidonic acid as mediators of hypersensitivity and inflammation. Med Clin North Am 1981;65:809-28.

12 Ford-Hutchinson AW, Bray MA, Doig MV, Shipley $\mathrm{ME}$, Smith MJH. Leukotriene $\mathrm{B}_{4}$, a potent chemokinetic and aggregating substance released from polymorphonuclear leukocytes. Nature 1980;286:264-5.

13 Kay AB. Eosinophils. In: Bienenstock J, ed. Immunology of the lung and upper respiratory tract. Toronto: McGraw-Hill, 1984:139-56.

14 Kay AB, Lee TH, Durham SR, et al. Mediators of hypersensitivity and inflammatory cells in early- and latephase asthmatic reactions. In: Kay AB, Austen KF, Lichtenstein LM, eds. Asthma: physiology, immunopharmacology and treatment. London: Academic Press, 1983:211-27.

15 Bach MK, Brashler JR, Fitzpatrick FA, et al. In vivo and In vitro actions of a new selective inhibitor of leukotriene C and D synthesis. In: Samuelsson B, Ramwell $\mathrm{PW}$, Paoletti R, eds. Advances in prostaglandin and thromboxane research. Vol 11. New York: Raven Press, 1983:39.

16 Dahlén SE, Hansson G, Hedqvist P, Bjorck T, Granstrom E, Dahlen B. Allergen challenge of lung tissue from asthmatics elicits bronchial contraction that correlates with release of leukotrienes $\mathrm{C}_{4} \mathrm{D}_{4}$ and $\mathrm{E}_{4}$. Proc Natl Acad Sci USA 1983;80:1712-6.

17 Robinson C, Holgate ST. Ionophore-dependent gener- ation of eicosanoids in human dispersed lung cells: modulation by 6,9-deepoxy 6,9-(phenylimino)- $\triangle$ 6.8-prostaglandin $I_{1}$. Biochem Pharmacol 1986;35: 1903-8.

18 Smith RJ, Sun FF, Bowman BJ, Iden SS, Smith HW, McGuire JC. Effect of 6,9-deepoxy-6,9(phenylimino)- $\triangle^{6,8}$-prostaglandin $I_{1},(U-60,257)$, an inhibitor of leukotriene synthesis on human neutrophil function. Biochem Biophys Res Commun 1982;109:943-9.

19 Cromwell O, Shaw RJ, Walsh GM, Kay AB. Inhibition of leukotriene $\mathrm{C}_{4}$ and $\mathrm{B}_{4}$ generation by human eosinophils and neutrophils [abstract]. Br J Pharmacol 1985;86:427P.

20 Bach MK, Brashler JR, Smith HW, Fitzpatrick FA, Sun FF, McGuire JC. 6,9-deepoxy-6,9-(phenylimino)- $\triangle$ ${ }^{6.8}$-prostaglandin $I_{1},(U 60,257)$ a new inhibitor of leukotriene C and D synthesis: in vitro studies. Prostaglandins 1982;23:759-77.

21 Johnson HG, McNee ML, Bach MK, Smith HW. The activity of a new, novel inhibitor of leukotriene synthesis in rhesus monkey. Ascaris reactors. Int Arch Allergy Appl Immunol 1983;70:169-73.

22 Bach MK. Prospects for the inhibition of leukotriene synthesis. Biochem Pharmacol 1984;33:515-21.

23 Howarth PH, Pao G J-K, Church MK, Holgate ST. Exercise and hyperventilation induced bronchoconstriction in asthma. The relevance of circulating basophils to measurements of plasma histamine. J Allergy Clin Immunol 1984;73:391-9.

24 Chai H, Farr RS, Froelich LA, et al. Standardisation of bronchial inhalation challenge procedures. J Allergy Clin Immunol 1975;56:323-7.

25 Armitage P. Statistical methods in medical research. Oxford: Blackwell Scientific Publications, 1980.

26 Bach MK, Griffin RL, Richards IM. Inhibition of the presumably leukotriene-dependent component of antigen-induced bronchoconstriction in the guinea pig by piriprost (U-60 257). Int Arch Allergy Appl Immunol 1985;77:264-6.

27 Lewis RA. Nebulisers for lung aerosol therapy. Lancet 1983;ii:849.

28 Hardy C, Robinson C, Lewis RA, Tattersfield AE, Holgate ST. Airway and cardiovascular responses to inhaled prostacyclin in normal and asthmatic subjects. Am Rev Respir Dis 1985;131:18-21.

29 Adams GK, Lichenstein LM. In vitro studies of antigeninduced bronchospasm: effect of antihistamine and SRS-A antagonist on response of sensitized guinea pig and airways to antigen. J Immunol 1979;122:555-62.

30 Burka JF. Pharmacological modulation of responses of guinea pig airways conntracted with antigen and calcium ionophore A23187. $\mathrm{Br} J$ Pharmacol 1985;85:411-20.

31 Howarth PH, Holgate ST. Astemizole, an $\mathrm{H}_{1}$-antagonist in allergic asthma [abstract]. J Allergy Clin Immunol 1985;75(suppl)166.

32 Ritchie DM, Sierchio JN, Capetola RJ, Rosenthale ME. SRS-A mediated bronchospasm by pharmacologic modification of lung anaphylaxis in vivo. Agents Actions 1981;11:396-401.

33 Cartier A, Thomson NC, Frith PA, Roberts R, Har- 
greave FE. Allergen induced increase in bronchial responsiveness to histamine: relationship to the late asthmatic response and change in airway calibre. $J$ Allergy Clin Immunol 1982;70:170-7.

34 Durham SR, Loegering DA, Gleich GJ, Kay AB. Eosinophils, non-specific bronchial responsiveness and allergen-induced late-phase asthmatic reactions [abstract]. J Allergy Clin Immunol 1985;75(suppl):148.

35 De Monchy JGR, Kauffman HF, Venge P, et al. Bronchoalveolar eosinophilia during allergen-induced late asthmatic reactions. Am Rev Respir Dis 1985;131:373-6.

36 Abraham WM, Delehunt JC, Yerger L, Marchette B. Characterization of a late phase pulmonary response following allergen challenge in allergic sheep. Am Rev Respir Dis 1983;128:839-44.

37 Fabbri LM, Aizawa H, O'Byrne PM, et al. An anti- inflammatory drug (BW755C) inhibits airway hyper- $\overline{\bar{\omega}}$ responsiveness induced by ozone in dogs. $J$ Allergy Clin Immunol 1985;76:162-6.

38 Ryan G, Latimer KM, Dolovich J, Hargreave FE. Bronchial responsiveness to histamine: relationship to diurnal variation of peak flow rate, improvement after bronchodilator and airway calibre. Thorax 1977;37:423-9.

39 Holgate ST,

Robinson

C. 6,9-deepoxy-6,9 (phenylimino)- $\Delta^{6.8}$ prostglandin $I_{1}(U-60,257)$ stimulates prostglandin $D_{2}$ and inhibits thromboxane $B_{2}$ release from ionophore challenged human dispersed lung cells. Br J Pharmacol 1984;83:60 3-5.

40 Hardy CC, Robinson C, Tattersfield AE, Holgate ST. The bronchoconstrictor effect of inhaled pros- $\overrightarrow{0}$ taglandin $\mathrm{D}_{2}$ in normal and asthmatic men. $N$ Engl $J$ Med 1984;311:209-13. 